- Lazarus, S S, and Shapiro, S H, Diabetes, 1973, 22, 499.

${ }^{7}$ Deckert, F W, et al, Federation Proceedings, 1977, 36, 990.

${ }^{8}$ Winter, S L, and Boyer, J L, New England Fournal of Medicine, 1973, 289, 1180 .

- Dulin, W E, and Wyse, B M, Proceedings of the Society for Experimental Biology and Medicine, 1969, 130, 992.

10 Wade, A, ed, Martindale. The Extra Pharmacopoeia, 27th edn, p 1691. London, Pharmaceutical Press, 1977.

11 Ganda, O M P, Rossini, A A, and Like, A A, Diabetes, 1976, 25, 595.

12 Williams, R H, Textbook of Endocrinology, 5th edn, p 519. London, W B Saunders, 1974.

13 Schein, P S, Proceedings of the Society for Experimental Biology and Medicine, 1969, 131, 517.

14 Gunnarsson, R, Berne, C, and Hellerström, C, Biochemical fournal, 1974, $140,487$.

\section{Wellcome Museum of the History of Medicine}

Since 1934, the extensive medical museum and library founded by Sir Henry Wellcome have been housed together at the Wellcome Institute in Euston Road. In 1972, acting on the advice of their History of Medicine Panel chaired by the late Lord Cohen of Birkenhead, the Wellcome trustees decided to create an international centre for research into the history of medicine. They proposed setting up an academic unit to foster undergraduate and postgraduate teaching as well as research. To make this development financially possible, the trustees were advised that they would need to find a new home for the museum collection, and they took legal advice on the possibility of offering it on indefinite loan to the Science Museum.

The Science Museum had several advantages: a prime site attracting over 3 million visitors a year; increased gallery space; a considerable library of its own; and its skill in cataloguing, evaluating, and displaying objects. After detailed negotiations the transfer was announced on 22 June 1976 by the Minister for the Arts, Education, and Science. Dr Brian Bracegirdle was appointed keeper of the new department at the Science Museum, to be entitled the Wellcome Museum of the History of Medicine. Dr Bracegirdle, an educationalist and biologist, is a specialist in the history of medicine, his current research relating to the history of microscopy and histology.

To make the museum collections more widely known to scholars and the medical profession, the trustees appointed Dr Christopher Lawrence to the staff of the Wellcome Institute, to be Wellcome medical historian at the Science Museum. Dr Lawrence's special interest is the history of diagnostic instruments in the general evolution of recent medical technology.

Since the new Wellcome Museum of the History of Medicine at the Science Museum began its work on 1 April 1977 a staff of over 30 people, partly funded by the Wellcome trustees, has been engaged. Much of its work is concerned with cataloguing items accepted from the trustees to standards suitable for eventual computer retrieval. This transfer of objects may take a further five years. To date, while the staff has been building up in both numbers and expertise, over 12000 items have been dealt with and trial computer runs evaluated.

Meanwhile, as the trustees had intended, academic activity has expanded in the Euston Road building. A Wellcome academic unit for the history of medicine has been established, composed of institute staff and those working in the unit of the history of medicine, which is housed in the department of anatomy and embryology of University
College London, with contributions from senior members of the Wellcome Museum. The close association of the institute with the college means that members of the Wellcome academic unit can have honorary appointments at University College London and can supervise candidates for higher degrees. The Wellcome academic unit, which is based on the institute's library, has five staff members, whose combined skills cover classical medicine, Arab medicine, the mediaeval and Renaissance periods, and the 18th and 20th centuries. An extensive and increasingly popular programme of undergraduate teaching courses is offered in University College London and in the University of London at large, including the intercalated BSc in the history of medicine. Thesis and dissertation candidates are supervised, while research into many aspects of the history of medicine, both scientific and social, is being carried out by members of the institute's staff and a series of visiting research fellows and students from various parts of the world.

The new galleries at the Science Museum total 16000 square feet, and for the present much of the permanent staff's time is spent on the arrangement of the displays. When the galleries open, in November 1980, they will cater for audiences ranging from young schoolchildren to postgraduate students. The lower gallery will concentrate on vivid models and reconstructions, with simple labelling intended for the younger and non-specialist visitor. The upper gallery will have more detailed displays. The Wellcome trustees intend to put a further large sum into the galleries, making a truly joint venture with the Science Museum. The Wellcome Museum is intended to expand its 20th century collection considerably, becoming an archive of contemporary medical objects, and it should become a centre for the academic study and teaching of the history of medical technology.

\section{Splenectomy for massive splenomegaly}

The normal spleen weighs only about $150 \mathrm{~g}$. Some enlargement is a feature of many diseases, but the spleen becomes massively enlarged (over $1500 \mathrm{~g}$ ) comparatively rarely. Massive splenomegaly may occur in the chronic leukaemias, myelofibrosis, the lymphomas, malaria, kala-azar, the storage diseases, and portal hypertension; and splenic cysts may occasionally cause massive enlargement. The diagnosis of splenomegaly may be confirmed by plain abdominal radiographs, radionuclide scans, or ultrasound; and occasionally splenic arteriography may be justifiable.

Splenectomy should not be undertaken in such patients just because the spleen is massively enlarged. Sometimes the sheer size of the organ may have caused symptoms such as pain or a feeling of heaviness; but the development of haematological problems, and especially hypersplenism, is a more convincing indication for operation. In some patients splenectomy may be required for diagnosis. Removal of a big spleen is associated with a greater morbidity and mortality than routine splenectomy, so that the surgeon needs to consider in detail his operative technique, and whether, for example, to infuse adrenaline into the splenic artery to reduce splenic size and the problem of bleeding. Individual surgeons also differ ${ }^{12}$ about the value of early ligation of the splenic artery, which is said to allow easier control of bleeding.

The benefits of splenectomy were clearly shown in a series 